\title{
Scott McCulloch
}

\section{GEOGRAPHY OF A HORSE SLAUGHTER}

I.

Miriam comes in large and soft. Everyone's taken back by her pride, agility, triumph. She's got all that's good in the new world. Miriam's perfect, down to the weeping blemish on her inner thigh. Everyone wants to keep her. But they can't. This is a home for lost dogs after all. Cole isn't even remotely swayed. He'll give her the shot. Cole will destroy her.

2.

The needle slips in like butter. Miriam kicks about, groans. There's all this big fuss, and then, as if everybody always stayed where they always were and nobody ever went anywhere, she collapses. By the plunge of a fat prick. Fossilised slaughter. Ritual. Miriam's dead on the flat tray of Cole's ute. He brings a tarpaulin over the carcass and wraps her like a dolmade. He still isn't phased, not even close. The cash feels thick in his pocket as he drives into the night.

3 .

Some of the money's for Cole, most of it's for the crematorium. He stuffs his cut into his left pocket, the other into his right. The crematorium won't be open until morning. Cole turns off and pulls into the brothel. He's welcomed. Everyone's happy to see him. It's as if they still recognise him from when his father brought him in when he was fourteen. He picks with ease: blonde, big tits, spray tan, mechanical eyelashes, mandarin character tattoo. She introduces herself as 'Felicity', takes him down a corridor and into a room with a light above the door. The door closes, the light comes on red. 
4 .

In the shower, Cole brings his foreskin down the knob of his cock and scrubs. He emerges from the bathroom hard; his knob burning crimson. Felicity lies spread-eagled on the plush bed. Cole proceeds to plunge his tonguelipsface into her crotch. He fumbles her cunt in his mouth. He runs his fingers through the mushroom bob of her pubic hair and presses down on her clit with his thumb. His pre-cum pastes itself on her ankle. Felicity's moans vibrate her stomach and arse. She jerks about, almost convulsing. Cole rocks in tune with the moves, inserting his tongue deeper into the flesh of her sex. He lifts her up by the arse and places her thighs on his shoulders. With one last burrowing dive, Cole licks the craters of her cunt, feels contractions round his darted tongue and...

... lying back down both of them heave in delight; guitars going out of tune in hard cases. Cole, hard as fuck, circles her navel with his fingertips. Goosebumps spread across her skin, raising small tufts of white hair on end. Felicity restrains and motions to the edge of the bed. Cole picks his pants up off the floor, reaches into his right pocket and exhausts the rest of his and the home's money. He cums in about thirty seconds.

5 .

Cole staggers out of the brothel, broke. He can't go to the crematorium. He can't go back to work. He just drives. Cole drives. Ballarat Road stretches out a long way ahead. The rising sun pours butter over lavender clouds. Cole slouches into the bucket seat, dying in revulsion. Some horses want to die, he thinks to himself, as the sadness of ejaculation gets chased around by a carcass in his head. The road keeps stretching on. Straight and narrow until a sudden jolt - a pothole in the road breaks into the bodykit of the ute. Cole's whole body is thrusted upwards, lifted, UP. The interior light splits his head open as the ute is propelled violently onto the side of the road, flinging the carcass off the flat tray and stretching it across the white lines. The ute keeps spinning out and finally jars among the thistles and the gravel on the side of the road and stops. Then, for an indeterminate amount of time, what seems like no time at all in a place where all ... Cole is out cold and everything and everyone is/are completely silent. Everything just stays silent. Everything is completely silent. And then it's broken; by the sizzle of Miriam's guts, blue and steaming on the asphalt; by the cacophony of a mother wailing. 